\title{
Cyanoacrylate Tissue Adhesive as a Membrane in Socket Preservation: In Vitro Cytotoxicity and Clinical Evaluation
}

Gerardo Mendoza Azpur ( $\sim$ Drgerardoodonto@yahoo.com )

Department of Periodontology, School of dentistry, Universidad Científica del Sur, Lima, Peru.

Junior ortiz

Scientific University of the South

Erick Valdivia

Scientific University of the South

Gabriela de Souza Balbinot

Federal University of Rio Grande do Sul

Fabricio Mezzomo Collares

Federal University of Rio Grande do Sul

Jonathan Meza Mauricio

Guarulhos University

Jamil A Shibli

Guarulhos University

\section{Research Article}

Keywords: Alveolar process, biocompatibility testing, bone regeneration, tissue adhesives

Posted Date: December 15th, 2020

DOl: https://doi.org/10.21203/rs.3.rs-125508/v1

License: (9) This work is licensed under a Creative Commons Attribution 4.0 International License. Read Full License 


\section{Abstract}

Background: Cyanoacrylate-based adhesives provide immediate hemostasis when applied; this is attributed to their ability to form a mechanical barrier in the surgical site, favoring the coagulation process and allowing control of bleeding. The purpose of the present study was to demonstrate the in vitro effect of cyanoacrylate-based tissue adhesive and the clinical evaluation of wound healing of freshly extracted sockets with adhesives applied on an exposed collagen membrane, for preservation of the alveolar ridge.

Methods: Cytotoxicity was evaluated with sulphoradamine B assay with primary fibroblasts from gingival tissue. The in vivo analysis was carried out in 10 patients needing extraction of single-rooted teeth, who met the inclusion and exclusion criteria and signed the term of free and informed consent. Alveolar preservation was carried out with a mineralized cortical allograft bone substitute and a resorbable collagen membrane that was intentionally left exposed. On the exposed membrane, the Periacryl® $90 \mathrm{HV}$ was applied as a barrier. The biocompatibility of the adhesive was assessed by the Early-Wound Healing Index (EHI) and Early Wound Healing Score (EHS), of perialveolar tissues at time intervals of 12, 30- and 60-days post-surgery.

Results: Reduced cell viability was observed for Periacryl® 90 HV when compared with cells without adhesive treatments. No postoperative complications were observed after the application of Periacryl® $90 \mathrm{HV}$ on perialveolar tissues.

Conclusion: The use of the Periacryl ${ }^{\circledR} 90 \mathrm{HV}$ cyanoacrylate-based tissue adhesive resulted in reduced fibroblast viability in vitro, and adequate results of wound closure in the clinical evaluation of EHI and EHS scores.

\section{Introduction}

Cyanoacrylates are acrylic resins that polymerize rapidly in the presence of a humid environment. Their adhesiveness, dependent on polymerization of the monomers in their composition, leads to bonding between structures [1]. Coover, in 1959, was the researcher who first recognized that the cyanoacrylates had adhesive properties; and since then these adhesives have commonly been used for daily applications [2]. In 1998, these adhesives were approved for use in surgical and traumatic wounds, after a series of improvements in their chemical composition $[3,4]$. The purpose of improvements was to reduce the cytotoxicity according to the number of alkyl groups and the number of chains in their composition, based on the conclusion that the larger the group and the longer the chain, the less toxic the adhesives would be, therefore, this would also reduce the risk of causing allergic reactions $[5,6]$.

The use of tissue adhesives in both medicine and dentistry is well known, especially in the closure of incisions instead of using sutures, decreasing the sensitivity, edema, erythema and tissue inflammation $[7,8]$.Several studies have been developed to use tissue adhesives as a substitute for sutures or as a complement to wound closure $[1,9]$. Among the main properties of interest in these tissue adhesives, are 
their bacteriostatic effects, which are explained by the strong electronegative charge of the polymer and the adhesive ability to form a mechanical barrier that prevents the entry of any debris or microorganisms into the wound [10].In addition, reports have indicated that the adhesives exhibited antibacterial effects against gram-positive bacteria, inhibiting the in vitro spread of bacillus subtilis growth [11].Cyanoacrylatebased adhesives provide immediate hemostasis when applied, and this is attributed to the ability to form a mechanical barrier within the surgical site, favoring the coagulation process and allowing control of the bleeding [12].

At present, due to the improvements in the chemical composition of these adhesives, they are no longer limited to superficial use only, but may now also be used in deep wounds and bone regenerative procedures such as a biomaterial fixing agent $[13,14]$. In addition, they have shown favorable and postsurgical results in mucogingival surgeries [15-17], and in other types of surgical approaches, without major complications $[18,19]$. The PeriAcryl $\circledast 90 \mathrm{HV}$ is a commercially available tissue adhesive composed of a blend of n-butyl cyanoacrylate and 2-octyl cyanoacrylate. These two cyanoacrylates have previously been studied, and by means of this combination, it is expected that the mechanical strength and cytotoxicity could be controlled, resulting in an adhesive that can effectively serve as a barrier without undesirable side effects [20-22]. Cytotoxicity is one of the three main biological responses studied in order to define whether a material has the ability to be biocompatible, and would obtain an adequate response when applied [23]. The other two biological responses are inflammation and wound healing that can be assessed in clinical evaluations [24]. In a previous clinical evaluation, the effect of cyanoacrylate-based adhesives was analyzed in the long-term, and showed adequate wound healing within a period of six months after tooth extraction [25]. Although this has contributed to understanding of the clinical performance of these adhesives, evaluation of the early stages of inflammation and wound healing have not previously been reported.

These parameters may be evaluated in a clinical scenario, based on the Early-Wound Healing Index (EHI) and Early Wound Healing Score (EHS), as accurate and reproducible methods to assess wound healing in periodontal soft tissues [26,20]. While the former describes the flap closure in 5 scores, considering the amount of fibrin and presence of necrosis, the latter, EHS, evaluates the early response of inflammation considering the clinical signs of reepithelization, hemostasis, and inflammation. Both the EHI and EHS have been used in the clinical evaluation of different periodontal and maxillofacial procedures and may be applied in the analysis of the socket healing process $[27,28,21]$. The purpose of the present study was to demonstrate the in vitro effect of cyanoacrylate-based tissue adhesive and the clinical evaluation of wound healing in freshly extracted sockets, with adhesives applied on an exposed collagen membrane, for preservation of the alveolar ridge.

\section{Materials And Methods}

\section{In vitro cytotoxicity}


Primary gingival fibroblasts were obtained from the gingival tissue of a healthy patient, after the study was approved by the Ethics Committee of Universidade Federal do Rio Grande do Sul. The primary cells were cultivated in Dubellco's minimum essential medium (DMEM) supplemented with $10 \%$ fetal bovine serum, and $100 \mathrm{IU} / \mathrm{mL}$ penicillin, $100 \mu \mathrm{g} / \mathrm{mL}$ streptomycin (Thermo Fischer Scientific, Waltham, Massachusets, USA) at $37^{\circ} \mathrm{C}$ and $5 \% \mathrm{CO}$, until the cells could be used for culture. To test the effect of adhesives on cell viability, three independent samples were poured into 24 -well plates and kept at $37^{\circ} \mathrm{C}$ for $72 \mathrm{~h}$ to allow polymerization of adhesives. After this, DMEM at $37^{\circ} \mathrm{C}$ was added on top of adhesives for $24 \mathrm{~h}$. The media in contact with the adhesives were used to treat the cells during the test. To perform the test, gingival fibroblast cells were seeded in 96 -well plates $\left(5 \times 10^{3}\right)$ and after $24 \mathrm{~h}$ the subconfluent cell monolayer was treated with conditioned media for $72 \mathrm{~h}$. Cells were cultivated with pure DMEM as a positive control. All conditions were tested in triplicate for each independent sample. After treatment, cells were fixed with $50 \%$ trichloroacetic acid (Sigma Aldrich) and left at $4^{\circ} \mathrm{C}$ for one hour. Cells were stained with $0.4 \%$ SRB solution to identify the cells that had viable proteins after the treatment. The stained monolayer was suspended in $10 \%$ Trisma and the quantification was performed at $560 \mathrm{~nm}$ in a Microplate Spectrophotometer (Multiskan GO, Thermo Fisher Scientific, USA). The absorbance values of cells treated with pure DMEM were used to normalize the viability of cells in contact with the conditioned medium, and thus, the percentage of viable cells was calculated.

\section{Clinical Evaluation}

A case series was performed by evaluating the post-operative healing patients, in a total of 10 postextraction alveoli of single-rooted teeth. The study protocol was carried out according to the guidelines of the 1975 Declaration of Helsinki, (revised in 2013) and approved by the ethics committee of the Universidad Cientifica del Sur, by registration 064-2018-PRE8. The study included male and female patients aged 20-70 years, in need of single-tooth extraction with mobility degree III (Miller, 1938), who had been referred to the University Cientifica del Sur for clinic treatment. The patients were excluded in case of smoking, systematic diseases, use of medications and when acute infection in teeth was identified. The corresponding medical records of the patients who met the inclusion and exclusion criteria were compiled, in which their important medical history was detailed. All patients included in the study signed the term of free and informed consent and were notified about the possible complications of the treatments.

A trained operator performed all the tooth extraction and socket preservation procedures. Periapical radiographs and cone beam computed tomography (CBCT) scans were used to record the position, angulation, remaining bone plates and anatomical repairs of the teeth to be extracted, to avoid complications at the time of tooth extraction. Prior to the extraction, asepsis of the oral cavity was performed with a $0.12 \%$ chlorhexidine-based antiseptic (Perioaid ${ }^{\circledR}$, treatment) for 30 seconds; and the patient's face was decontaminated with a $10 \%$ iodopovidone solution. The teeth were anesthetized by applying topical anesthesia with $20 \%$ benzocaine gel (Benzotop $\AA$ ), and then the infiltrative anesthesia was administered, using lidocaine $2 \%$, with epinephrine 1:80 000 (New Stetic $®$ ). Sulcular incision and vertical liberating incisions were made with a $15 \mathrm{C}$ blade, and full-thickness flap elevation with the use of 
a Molt curette, with the purpose of obtaining direct visualization of the vestibular bone plate. The teeth were excised with the use of a peristome, and once the tooth had been dislocated, an anterior forceps or elevator was used to perform avulsion, depending on the teeth to be extracted and the surrounding structures. On conclusion of the extraction, the walls of the alveolus were cleaned using a Lucas 48 curette, and washed with a $0.9 \%$ Sodium Chloride solution. After socket preparation, the alveolar flange preservation technique was performed, in which 0.5 grams of 300-500 $\mu \mathrm{m}$ mineralized cortical allograft (Puros ${ }^{\circledR}$, Zimmer Biomet dental, Miami, USA) was applied, compacted into the alveolus and covered with a collagen membrane (OSSIX ® PLUS). The vestibular flap was re-positioned without traction and an internal cross-type suture stitch and single stitches made with monofilament non-absorbable e-PTFE suture thread with a $16 \mathrm{~mm} 3$ / 8c cutting needle ( GORE-TEX®) (Figure 1) were used on the proximal surfaces to close the wound, but intentionally leaving the membrane exposed.

After conclusion of the alveolar flange preservation technique, the cyanoacrylate-based tissue adhesive (PeriAcryl® $90 \mathrm{HV}$ ) was applied both on the perialveolar stitches and on the intentionally exposed membrane, creating a protective film, by using a plastic dosing pipette, in accordance with the manufacturer's instructions. The amount of adhesive to be used depended on the size of the exposed membrane to be covered in each case as shown in (Figure 1). The patients were provided with postsurgical recommendations with regard to restriction on brushing in the area, and were instructed to use $0.12 \%$ chlorhexidine-based mouthwashes every 12 hours for 2 weeks. All patients received postoperative antibiotic and anti-inflammatory therapy based on $500 \mathrm{mg}$ Amoxicillin taken every 8 hours for 10 days, and $500 \mathrm{mg}$ Paracetamol, depending on pain experienced.

Post-surgical controls were performed at time intervals of 12,30 and 60 days after surgery, in which the presence of stitches (first control), and the presence of tissue adhesive was verified. Signs of inflammation such as edema, pain, erythema, suppuration and loss of the collagen membrane were evaluated, according to Early-Wound Healing Index (EHI) and Early Wound Healing Score (EHS) by a single calibrated operator. The calibration was performed by the Kappa index for the intra-operator correlation. The EHI of each patient was classified according to different scores considering closure of the flap:

1. Complete closure of the flap without fibrin line

2. Complete closure of the flap with fibrin line

3. Complete closure of the flap with fibrin clots present

4. Incomplete flap clot with partial tissue necrosis

5. Incomplete closure of the flap with total tissue necrosis, more than $50 \%$ of the flap.

The EHS was classified according to clinical evidence of epithelium formation (SCR); clinical evidence of hemostasis (SCH); and clinical evidence of inflammation (SCl):

SCR: 
- 0 pts: distance between the margin of the incision,

- 3 pts: margins of the incision in contact,

- 6 pts: connected margins of the incision.

$\mathrm{SCH}:$

- 0 pts: bleeding of the incision margins,

- 1 pt: fibrin in the margins of the incision,

- 2 pts: absence of fibrin in the margin of the incision.

SCl:

- 0 pts: redness in $>50 \%$ of the length of the incision and/or pronounced inflammation,

- 1 pts: redness of the implies $<50 \%$ of the length of the incision,

- 2 pts; absence of the redness along the incision length.

\section{Results}

The viability of cells in contact with the conditioned medium was calculated based on the absorbance at $560 \mathrm{~nm}$ found for the positive control. The percentage of viable cells was $39.66 \%( \pm 6,31)$. In the clinical evaluation, no postoperative complication was observed, and all patients attended to the three follow-up appointments. Analysis of the effect of the adhesive on EHI (Table 1). All the sockets showed a complete flap closure with the presence of fibrin clots at 12 days, four alveoli showed complete scarring with fibrin clots; four alveoli exhibited complete scarring with fibrin line; two alveoli showed complete scarring without fibrin lines at 30 days. At 60 days all the surgical sites showed complete closure of the flap without the presence of fibrin lines.

For EHS (Table 2 and Figure 2), at 12 days, four cases exhibited a visible distance between the margins of the incision; six cases had margins of contact incision; nine cases had presence of fibrin in the incision margins; and a single alveolus showed absence of fibrin in the incision margins. In this analysis, $50 \%$ of the sockets had erythema to an extent larger than $50 \%$ of the length of the incision extension.

At 30 days, $50 \%$ of the sockets exhibited fused margins of the incisions, absence of fibrin in the margins of the incision and seven alveoli had less than $50 \%$ of the length of the incision extension. After 60 days, $100 \%$ of the sockets exhibited fused surgical margins, absence of fibrine in the margins of the incision and absence of erythema and inflammation. This section could be divided into subheadings. It should provide a concise and precise description of the experimental results, their interpretation as well as the experimental conclusions that can be drawn.

\section{Discussion}


Numerous methods have been proposed over the years to evaluate wound healing in soft and perialveolar tissues [22]. In this study, cyanoacrylate-based adhesives were tested for their in vitro cytotoxicity and clinical performance in freshly extracted sockets. In these analyses, reduced cell viability was found, while a complete closure of wound was observed considering the EHI and EHS analysis, showing that the adhesive studied was safe with regard to tissue compatibility.

The in vitro cell viability was used to test the response of primary gingival fibroblasts in contact with the products of cyanoacrylate-based adhesives. Reduction in cell viability was observed in cells that were placed in contact with media containing Periacryl® $90 \mathrm{HV}$ tissue adhesive. This behavior could be explained for two reasons in the anionic polymerization of cyanoacrylate materials. The first was the exothermic reaction of polymerization, which may lead to increase in temperature in surrounding tissues; the second was the release of degradation products from the reaction, in these cases, mainly cyanoacetate and formaldehyde [29]. It should be considered that a two-dimensional cell culture approach was used in this evaluation. Although this model is recommended by ISO 10993-12, it is known that this direct contact between cells and highly concentrated material extracts may result in an overestimation of the results [30]. Despite the limitations of this in vitro analysis, indirect cell cytotoxicity is a widely used method for assessing the potential of materials to promote cytotoxicity. Moreover, previous studies have shown conflicting results regarding the toxicity of cyanoacrylate adhesives [31,32]. These differences may be related to the chemical structure of their alkyl chains in the adhesives [31-33]. Short length chains (e.g. ethyl and methyl) are more prone to degradation. leading to increase in leached toxic products, whereas long chains are more resistant to degradation [31]. The tissue adhesive used in the present study is a blend of n-butyl cyanoacrylate and 2-octyl cyanoacrylate and studies that have attempted to evaluate the cytotoxicity of adhesives with similar composition, showed a level of cytotoxicity around 40\% [34] 60\% [31,35] which is higher than the values found for shorth length alkyl chains $[31,34]$. In the present study the cell viability was $39.66 \%$, which was similar to findings of previous reports of similar adhesives, and lower when compared with the ISO 10993-12 specification that considers $70 \%$ to be the minimum requirement for toxicity in biomedical materials [34].

In addition to the local effect on cytocompatibility, further studies have addressed the systemic effect of these materials on animal models. The effect of cyanoacrylate-based materials may locally and systemically affect tissues, as observed in animal models, in which there were no effects on hepatic, renal and blood biochemical profiles, and in histologic analyses [36,37]. In the cases of the studies cited above, the release of potentially toxic products after the degradation of cyanoacrylate tissue adhesives was unable to affect animals at a systemic level. The accumulation of cyanoacetate and formaldehyde may cause inflammation in tissues in contact with these products both locally and systemically. The $n$ butyl cyanoacrylate was tested in the cited studies and no toxic effect on animals was observed. Although these findings were observed in vitro, no effect on wound healing was observed in the clinical evaluation, at least, in the short period of time. No postoperative complication was observed for any patient during the 60-day follow-up. This is an important observation, as the collagen membrane in the procedures was left exposed after the flap repositioning. The exposure of membrane after guided bone regeneration membranes is known to increase the prevalence of postoperative bacterial infection in 
surgical sites [38]. Furthermore, the cyanoacrylate-based adhesive (Periacryl® $90 \mathrm{HV}$ ) exhibited a hemostatic effect on the wound after 12 days, when the sockets already had fibrin formation, indicating a beginning of wound healing [39]. The formation of a film caused an interruption between the edges of the wound, generating redness and inflammation of the surgical area, however, these phenomena were only present in some alveoli, and complete healing was obtained at the end of the follow-up, with the highest scores being obtained in both the EHI and EHS scales of healing measurement. These results elucidated the ability of cyanoacrylate adhesives to adequately promote wound closure, facilitating healing after tooth extraction ${ }^{1}$ and avoiding the penetration of bacteria could promote postoperative complications. Furthermore, the inflammation that might have been promoted by degradation products of cyanoacrylatebased adhesives was not observed in the bonded tissues.

Cyanoacrylate-based adhesives may be an easy and conventional strategy for promoting the healing of soft tissue in different procedures $[1,8,9]$. Although some studies have attempted to analyze the cytocompatibility of these materials, few reports were found regarding the clinical determination of biocompatibility through healing and inflammation of the perialveolar tissues in regenerative treatment. Therefore, this case series is important to report the clinically perceivable changes that occurred in the tissues with the approached used, as an alternative to flap closure in alveolar ridge preservation treatments. However, long-term follow-up and studies with larger samples must be conducted to observe both soft and hard tissue behavior after the use of cyanoacrylate-based adhesive for wound closure.

\section{Conclusions}

Although the in vitro data showed a reduction in fibroblast viability, no effect on wound healing was found for the cyanoacrylate-based tissue adhesives. Based on the in vitro and in vivo findings it was possible to conclude that the cyanoacrylate-based tissue adhesive may be a suitable adjuvant material in wound closure in socket preservation treatments.

\section{Declarations}

Acknowledgements: The authors acknowledge all participants in the study.

Authors' contributions : Conceptualization, G.M.A.; E.V. and G.S.B; methodology, G.M.A.; E.V. and G.S.B and J.A.S; formal analysis, G.M.A.; E.V. and G.S.B; investigation, G.M.A.; E.V.; G.S.B and F.M.C.; data curation, G.M.A.; E.V; G.S.B and F.M.C; writing and original draft preparation, G.M.A.; J.O.; E.V. and G.S.B; writing review and editing, J.M.M.; G.M.A.; E.V.; G.S.B and J.A.S; supervision, G.M.A; project administration G.M.A.; E.V. and G.S.B; All authors read and approved the final manuscript.

Funding: This research received no external funding.

\section{Availability of data and materials}

The datasets used and analyzed during the current study are available from the corresponding 
author on reasonable request.

\section{Ethics approval and consent to participates}

The study was approved by the ethics committee of the Universidad Cientifica del Sur, by registration 0642018-PRE8. All participating patients gave informed written consent to participate in this study and for publications of the obtained data.

\section{Consent for publication}

Not applicable.

\section{Competing interests}

The authors declare that they have no competing interests

\section{Author details}

${ }^{1}$ Department of Periodontology, School of dentistry, Universidad Científica del Sur, Lima, Peru. ${ }^{2}$ Dental Materials Laboratory, School of Dentistry, Federal University of Rio Grande do Sul. ${ }^{3}$ Department of Periodontology and Oral Implantology, Dental Research Division, University of Guarulhos, SP, Brazil.

\section{References}

1. Pascual G, Sotomayor S, Rodríguez M, Pérez KB, Kühnhardt A, Fernández GM, San Román J, Bellón JM. Cytotoxicity of Cyanoacrylate-Based Tissue Adhesives and Short-Term Preclinical In Vivo Biocompatibility in Abdominal Hernia Repair. PLoS One. 2016; 11(6): 1 - 22.

2. Coover HW, Joyner FB, Shearer NH, Wicker TH. Chemistry and performance of cyanoacrylate adhesives. J Soc Plast Surg Eng. 1959; 15: 413 - 17.

3. Soni A, Narula R, Kumar A, Parmar M, Sahore M, Chandel M. Comparing Cyanoacrylate Tissue Adhesive and Conventional Subcuticular Skin Sutures for Maxillofacial Incisions-A Prospective Randomized Trial Considering Closure Time, Wound Morbidity, and Cosmetic Outcome. J Oral and Maxillofac Surg. 2013; 71(12): 2152 - 60.

4. Gennari R, Rotmensz N, Ballardini B, Scevola S, Perego E, Zanini V, Costa A. A prospective, randomized, controlled clinical trial of tissue adhesive (2-octylcyanoacrylate) versus standard wound closure in breast surgery. Surgery. 2004; 136 (3): 593 - 99.

5. Lacerda SR, Roberto BMS, Carvalho FG, Dos Santos A, Dantas AFM. Histological analysis of biocompatibility of different surgical adhesives in subcutaneous tissue. Microsc. Res Tech. 2019; 82 (7): 1184 - 1190.

6. Quinn J, Lowe L, Mertz M. The effect of a new tissue-adhesive wound dressing on the healing of traumatic abrasions. Dermatology. 2000; 201(4):343 - 46. 
7. Borie E, Rosas E, Kuramochi G, Etcheberry S, Olate S, Weber B. Oral Applications of Cyanoacrylate Adhesives: A Literature Review. Biomed Res Int. 2019; 2019: 1 - 6.

8. Sagar P, Prasad K, Lalitha RM, Ranganath K. Cyanoacrylate for Intraoral Wound Closure: A Possibility?. Int J Biomater. 2015; 2015: 1 - 6.

9. Vastani A, Maria A. Healing of intraoral wounds closed using silk sutures and isoamyl 2cyanoacrylate glue: a comparative clinical and histologic study. J Oral Maxillofac Surg. 2013; 71 (2): 241 - 48.

10. Malhotra V, Dayashankara RJK, Arya V, Sharma S, Singh S, Luthra P. Evaluating the use of octyl-2cyanoacrylate in unilateral cleft lip repair. Natl J Maxillofac Surg. 2016; 7 (2):153 - 58.

11. Montanaro L, Arciola CR, Cenni E, Ciapetti G, Savioli F, Filippini F. Cytotoxicity, blood compatibility and antimicrobial activity of two cyanoacrylate glues for surgical use. Biomaterials. 2001; 22 (1): 59 66.

12. Grimaldi L, Cuomo R, Brandi C, Botteri G, Nisi G, D’Aniello C. Octyl-2-cyanoacrylate adhesive for skin closure: eight years experience. In Vivo. 2015; 29(1): 145 - 48.

13. De Santis E, Silva ER, Martins ENC, Favero R, Botticelli D, Xavier SP. Healing at the Interface Between Autologous Block Bone Grafts and Recipient Sites Using n-Butyl-2-Cyanoacrylate Adhesive as Fixation: Histomorphometric Study in Rabbits. J Oral Implantol. 2017; 43(6): 447 - 55.

14. Salata LA, Mariguela VC, Antunes AA, Grossi-Oliveira G, Almeida A, Taba M. Short-term evaluation of grafts fixed with either N-butyl-2-cyanocrylate or screws. J Oral Maxillofac Surg. 2014; 72 (4): 676 82.

15. Tavelli L, Asa'ad F, Acunzo R, Pagni G, Consonni D, Rasperini G. Minimizing Patient Morbidity Following Palatal Gingival Harvesting: A Randomized Controlled Clinical Study. Int J Periodontics Restorative Dent. 2018; 38 (6): 127 - 34.

16. Pérez M, Fernández I, Márquez D, Bretaña RM. Use of N-butyl-2-cyanoacrylate in oral surgery. biological and clinical evaluation. Artif Organs. 2000; 24 (3): 241 - 43.

17. Gümüş P, Buduneli E. Graft stabilization with cyanoacrylate decreases shrinkage of free gingival grafts. Aust Dent J. 2014; 59 (1): 57 - 64.

18. Cooper JM, Paige KT. Primary and revision cleft lip repairs using octyl-2-cyanoacrylate. J Craniofac Surg. 2006; 17 (2): 340 - 43.

19. Choi BH, Kim BY, Huh JY, Lee SH, Zhu SJ, Jung JH. Cyanoacrylate adhesive for closing sinus membrane perforations during sinus lifts. J Craniomaxillofac Surg. 2006; 34 (8): 505 -9.

20. Marini L, Sahrmann P, Rojas MA, Cavalcanti C, Pompa G, Papi P, Pilloni A. Early Wound Healing Score (EHS): An Intra- and Inter-Examiner Reliability Study. Dent J. 2019; 7 (3): 86 - 96.

21. Harnack L, Boedeker RH, Kurtulus I, Boehm S, Gonzales J, Meyle J. Use of platelet-rich plasma in periodontal surgery a prospective randomised double blind clinical trial. Clin Oral Investig. 2009; 13 (2) :179 - 87. 
22. Hamzani Y, Chaushu G. Evaluation of early wound healing scales/indexes in oral surgery: A literature review. Clin Implant Dent Relat Res. 2018; 20 (6): 1030 - 35.

23. Dzobo K, Thomford NE, Senthebane DA, Shipanga H, Rowe A, Dandara C. Advances in Regenerative Medicine and Tissue Engineering: Innovation and Transformation of Medicine. Stem Cells Int. 2018; 2018: 1- 24.

24. Giannobile WV, Jung RE, Schwarz F. Evidence-based knowledge on the aesthetics and maintenance of peri-implant soft tissues: Osteology Foundation Consensus Report Part 1-Effects of soft tissue augmentation procedures on the maintenance of peri-implant soft tissue health. Clin Oral Implants Res. 2018; 29 (15): 7 - 10.

25. Nevins M, Mendoza-Azpur G, Angelis ND, Kim DM. The biocompatibility of cyanoacrylate tissue adhesive in conjunction with a collagen membrane for providing soft and hard tissue regeneration in extraction socket preservation procedures. International Journal of Periodontics and Restorative Dentistry. 2018; 38: 37 - 42.

26. Wachtel H, Schenk G, Böhm S, Weng D, Zuhr O, Hürzeler MB. Microsurgical access flap and enamel matrix derivative for the treatment of periodontal intrabony defects: a controlled clinical study. J Clin Periodontol. 2003; 30 (6): 496 - 504.

27. Wang L, Liu L, Song W, Hu F, Zhou J, Ji Q. Refinement and Evaluation of Modified Minimally Invasive Harvest Technique for Subepithelial Connective Tissue. J Craniofac Surg. 2018; 29 (5): 1287 - 90.

28. Fickl S, Fischer KR, Jockel-Schneider Y, Stappert CFJ, Schlagenhauf U, Kebschull M. Early wound healing and patient morbidity after single-incision vs. trap-door graft harvesting from the palate a clinical study. Clin Oral Investig. 2014; 18 (9): 2213 - 19.

29. Vauthier C, Dubernet C, Fattal E, Pinto-Alphandary H, Couvreur P. Poly (alkylcyanoacrylates) as biodegradable materials for biomedical applications. Adv Drug Deliv Ver. 2003; 55(4): 519 - 48.

30. Przekora A. The summary of the most important cell-biomaterial interactions that need to be considered during in vitro biocompatibility testing of bone scaffolds for tissue engineering applications. Mater Sci Eng C Mater Biol Appl. 2019; 97: 1036 - 51.

31. Mizrahi B, Stefanescu CF, Yang C, Lawlor MW, Ko D. Langer R, Kohane DS. Elasticity and safety of alkoxyethyl cyanoacrylate tissue adhesives. Acta Biomater. 2011; 7(8): 3150 - 7.

32. Lim JI, Lee WK. Enhanced biocompatibility and adhesive properties by aromatic amino acid-modified allyl 2-cyanoacrylate-based bio-glue. Colloids Surf B Biointerfaces. 2014; 122: 669 - 73.

33. Damante CA, Cardoso MV, Karam PSB, Haiter AC, Santana AC, Greghi SL, et al. Evaluation of Regular Market Ethyl Cyanoacrylate Cytotoxicity for Human Gingival Fibroblasts and Osteoblasts. Surg Infect. 2020; 21 (1): 29 - 34.

34. De Sena LÁ, De Almeida MS, De Oliveira Fernandes GV, Bretaña RM, Castro-Silva IG, Granjeiro JS, Achete CA. Biocompatibility of wollastonite-poly (N-butyl-2-cyanoacrylate) composites. J Biomed Mater Res B Appl Biomater. 2014; 102 (6): 1121 - 29.

35. Lee YJ, Jung GB, Choi S, Lee G, Kim JH, Son HS, Bae H, Park HK. Biocompatibility of a Novel Cyanoacrylate Based Tissue Adhesive: Cytotoxicity and Biochemical Property Evaluation. Plos One. 
2013; 8 (11): 1 - 9.

36. López-Jornet P, Camacho-Alonso F, Gómez-García F. Evaluation of biochemical the two cyanoacrylates: an experimental study in rats. J Biomater Appl. 2009; 24 (3): 197 - 207.

37. Inal S, Yilmaz N, Nisbet C, Güvenç T. Biochemical and histopathological findings of N-butyl-2cyanoacrylate in oral surgery: an experimental study. Oral Surg Oral Med Oral Pathol Oral Radiol Endod. 2006; 102 (6): 14 -17.

38. Garcia IM, Leitune VCB, Balbinot GDS, Samuel SMW, Collares FM. Influence of niobium pentoxide addition on the properties of glass ionomer cements. Acta Biomater Odontol Scand. 2016; 2 (1): 138 $-43$.

39. Del Fabbro M, Bucchi C, Lolato A, Corbella S, Testori T, Taschieri S. Healing of Postextraction Sockets Preserved with Autologous Platelet Concentrates. A Systematic Review and Meta-Analysis. J Oral Maxillofac Surg. 2017; 75 (8): 1601 - 15.

\section{Tables}

Table 1. Scores for EHI analysis after post-operative time intervals of 12, 30 and 60 days

\begin{tabular}{|llll|}
\hline ALVEOLUS & $\mathbf{1 2}$ days & $\mathbf{3 0}$ days & $\mathbf{6 0}$ days \\
\hline$\# 1$ & 3 & 2 & 1 \\
\hline$\# 2$ & 3 & 3 & 1 \\
\hline$\# 3$ & 3 & 2 & 1 \\
\hline$\# 4$ & 3 & 3 & 1 \\
\hline$\# 5$ & 3 & 2 & 1 \\
\hline$\# 6$ & 3 & 1 & 1 \\
\hline$\# 7$ & 3 & 1 & 1 \\
\hline$\# 8$ & 3 & 3 & 1 \\
\hline$\# 9$ & 3 & 3 & 1 \\
\hline$\# 10$ & 3 & 2 & 1 \\
\hline
\end{tabular}

Table 2. SCR. SCH and SCl scores as part of the EHS analysis of wound healing in perialveolar tissue. 


\begin{tabular}{|c|c|c|c|c|c|c|c|c|c|}
\hline & SCR & & & $\mathrm{SCH}$ & & & $\mathrm{SCl}$ & & \\
\hline Post-surgical controls & $12 d$ & $30 d$ & $60 d$ & $12 d$ & $30 d$ & $60 d$ & $12 d$ & $30 d$ & $60 d$ \\
\hline$\# 1$ & 0 & 6 & 6 & 1 & 2 & 2 & 1 & 1 & 2 \\
\hline \#2 & 3 & 3 & 6 & 1 & 2 & 2 & 1 & 1 & 2 \\
\hline$\# 3$ & 3 & 6 & 6 & 1 & 2 & 2 & 0 & 2 & 2 \\
\hline$\# 4$ & 3 & 3 & 6 & 1 & 1 & 2 & 1 & 1 & 2 \\
\hline \#5 & 0 & 3 & 6 & 1 & 1 & 2 & 1 & 1 & 2 \\
\hline \#6 & 3 & 6 & 6 & 1 & 2 & 2 & 0 & 1 & 2 \\
\hline$\# 7$ & 3 & 6 & 6 & 1 & 2 & 2 & 0 & 2 & 2 \\
\hline \#8 & 0 & 3 & 6 & 2 & 2 & 2 & 1 & 2 & 2 \\
\hline \#9 & 0 & 3 & 6 & 1 & 1 & 2 & 0 & 1 & 2 \\
\hline$\# 10$ & 3 & 3 & 6 & 1 & 1 & 2 & 0 & 1 & 2 \\
\hline
\end{tabular}

Figures 


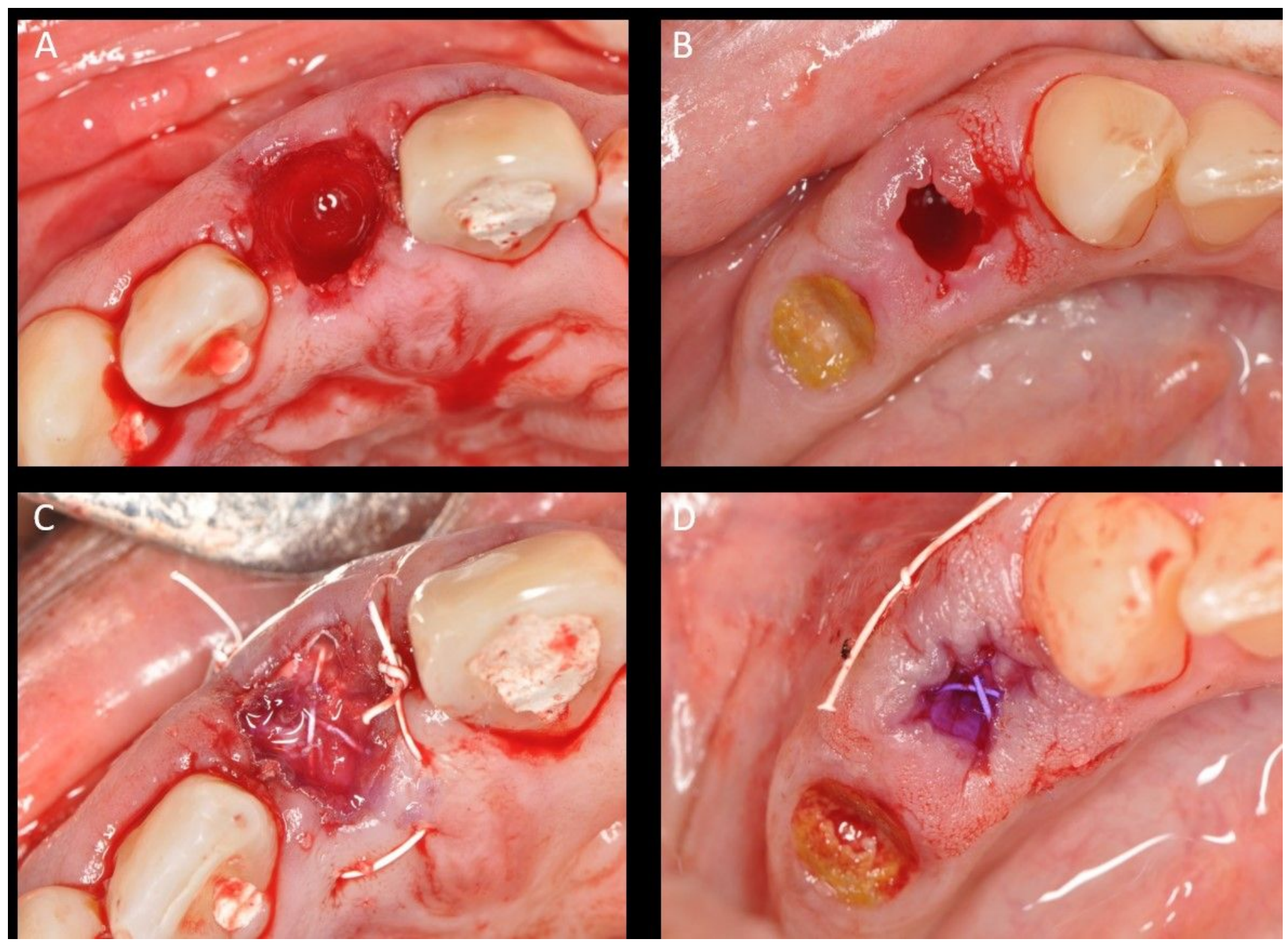

\section{Figure 1}

Surgical procedures for clinical evaluation of cyano-acrylate-based tissue adhesives: (A) tooth extraction; (B) the empty socket after tooth extraction; (C) socket preservation with socket filling and collagen membrane; (D) the cyanoacrylate-based tissue adhesive (PeriAcryl ${ }^{\circledR} 90 \mathrm{HV}$ ) applied to membrane. 


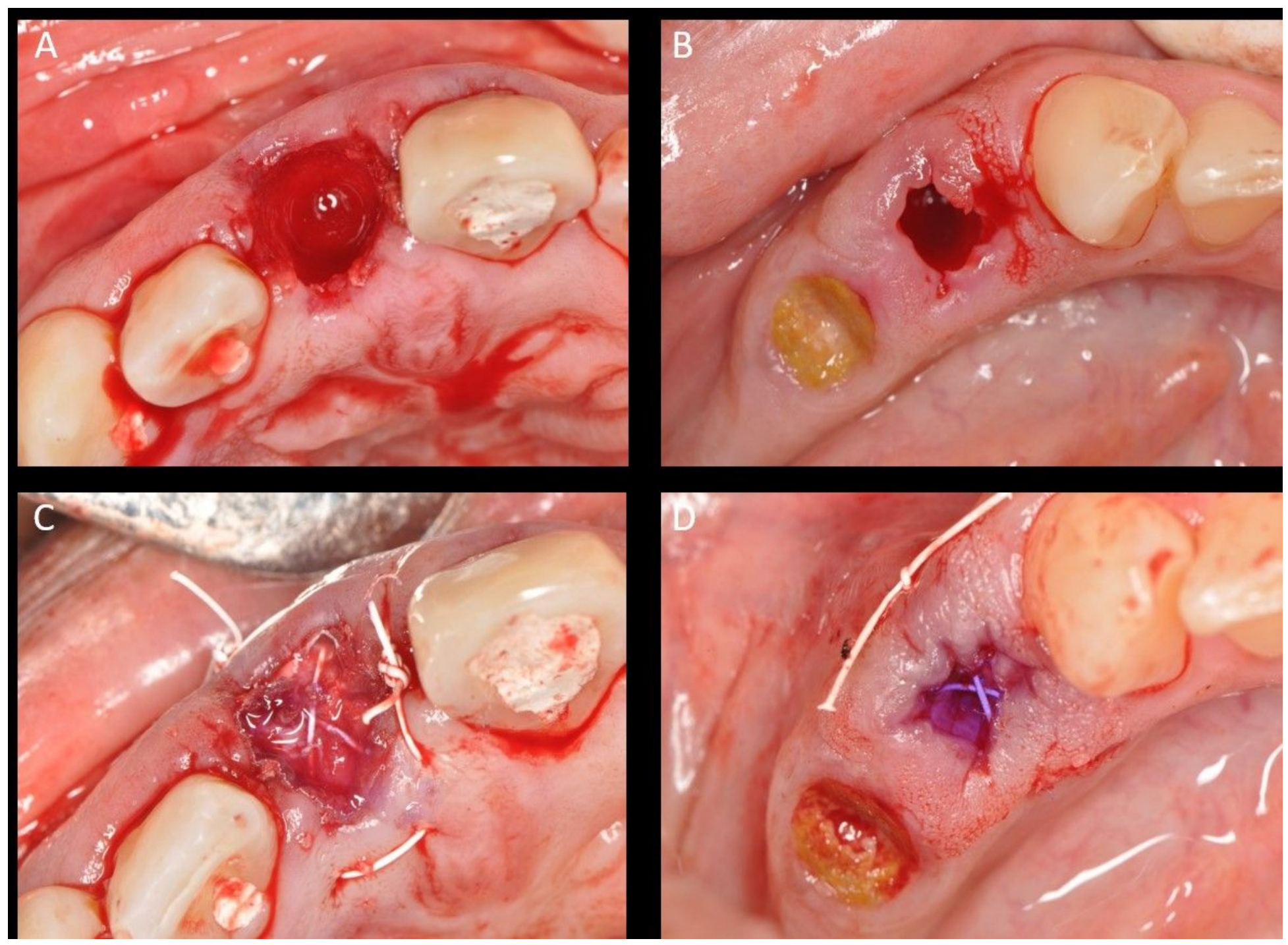

\section{Figure 1}

Surgical procedures for clinical evaluation of cyano-acrylate-based tissue adhesives: (A) tooth extraction; (B) the empty socket after tooth extraction; (C) socket preservation with socket filling and collagen membrane; (D) the cyanoacrylate-based tissue adhesive (PeriAcryl ${ }^{\circledR} 90 \mathrm{HV}$ ) applied to membrane. 


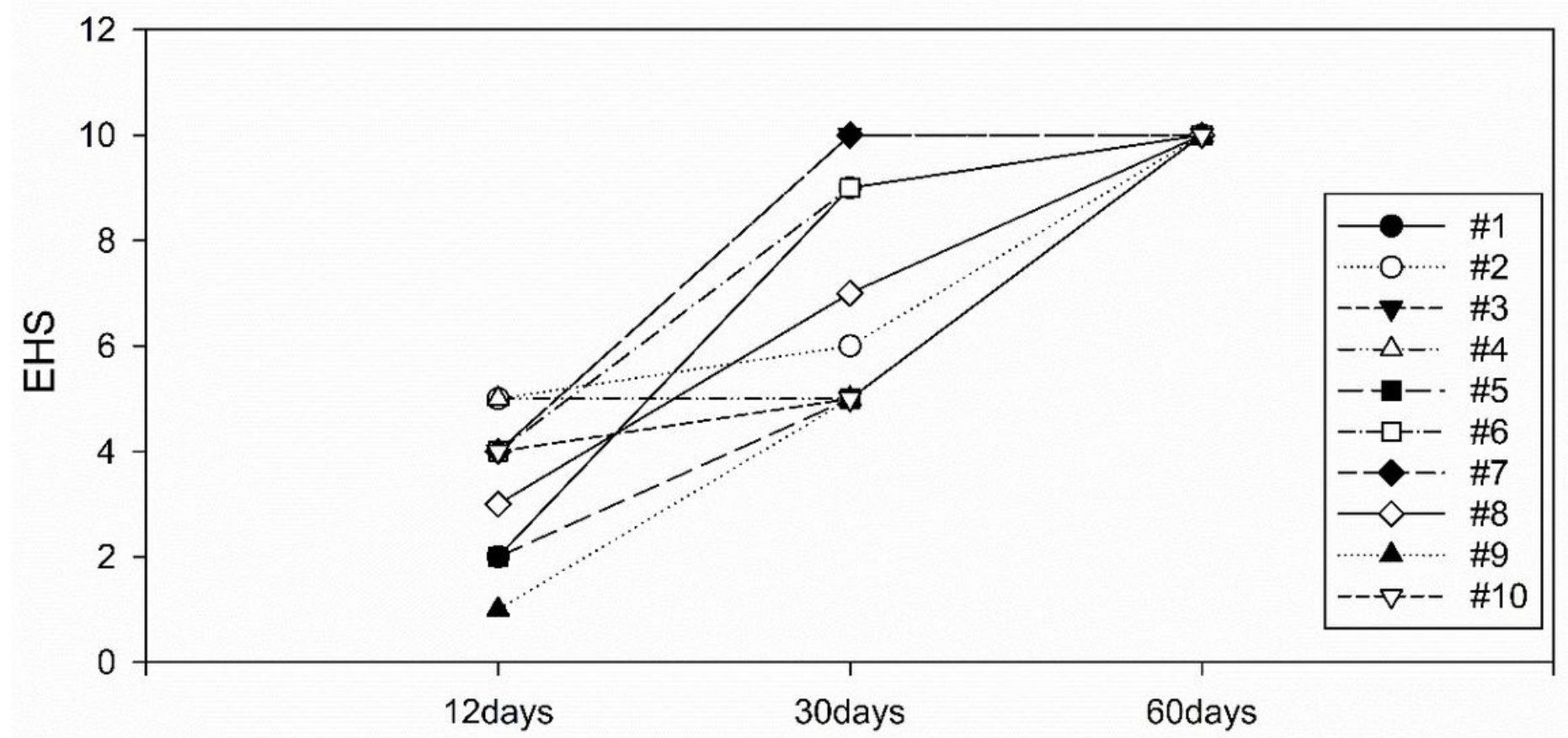

Figure 2

EHS values after time intervals of 12, 30 and 60 days after application of adhesives in perialveolar tissue.

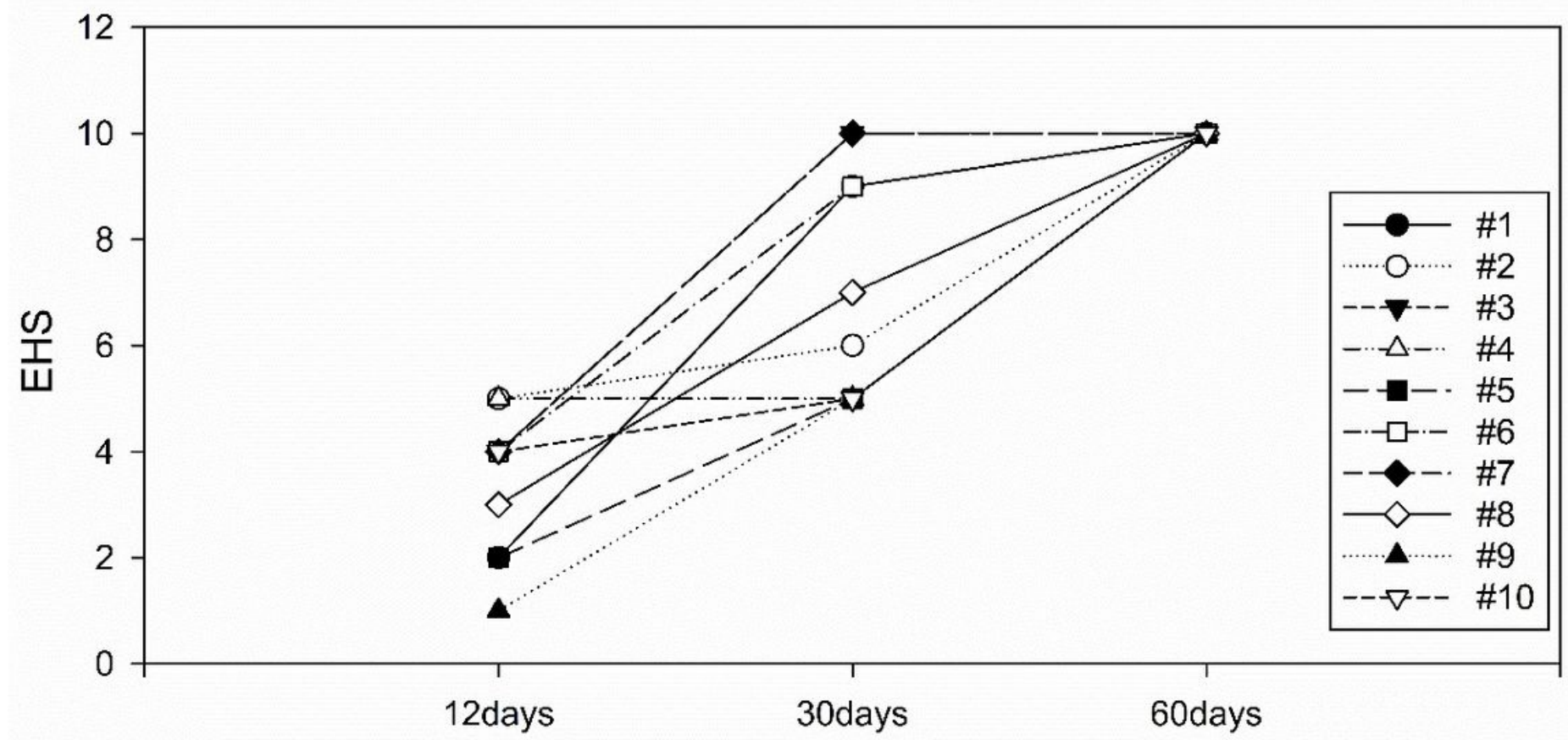

Figure 2

EHS values after time intervals of 12, 30 and 60 days after application of adhesives in perialveolar tissue. 